ORIENTAL JOURNAL OF CHEMISTRY

An International Open Free Access, Peer Reviewed Research Journal

www.orientjchem.org
ISSN: 0970-020 X

CODEN: OJCHEG

2014, Vol. 30, No. (4):

Pg. 1535-1543

\title{
Investigation of the Effects of Ionic Liquids Pretreatments and Enzymatic Hydrolysis of Kempas, Koompassia malaccensis
}

\section{POH LEE LOH, NUR HASYAREEDA HASSAN* and MUHAMMAD RAHIMI YUSOP}

\author{
School of Chemical Sciences and Food Technology, Faculty of Science and Technology, \\ Universiti Kebangsaan Malaysia, 43000 Bangi, Selangor, Malaysia. \\ ${ }^{*}$ Corresponding author E-mail: syareeda@ukm.edu.my
}

http://dx.doi.org/10.13005/ojc/300411

(Received: August 05, 2014; Accepted: September 20, 2014)

\begin{abstract}
The aim of this study is to investigate ionic liquids (ILs) pretreatment on kempas composition, structure and enzymatic digestibility. Ground kempas (Koompassia malaccensis) was pretreated with 1-butyl-3-methylimidazolium acetate ([Bmim][OAc]), 1-butyl-3-methylimidazolium chloride $([\mathrm{Bmim}] \mathrm{Cl})$ and 1-butyl-3-methylimidazolium trifluoromethansulfonate ([Bmim] $[\mathrm{OTf}])$, at $120^{\circ} \mathrm{C}$ for 6 and $12 \mathrm{~h}$. The cell wall composition and structure of the kempas before and after the ILs pretreatment were observed and characterized using FESEM, ATR FT-IR and XRD. After the pretreatment, enzymatic hydrolysis was carried out to identify the reducing sugars yields using DNS method. Overall, DNS assay showed that the reducing sugars yields of [Bmim][OAc]pretreated kempas with $6 \mathrm{~h}$ and $12 \mathrm{~h}$ pretreatment were highest among the ILs regenerated cellulose which are in agreement with the findings of FESEM, ATR FT-IR and XRD. Therefore, shorter-time IL pretreatment is more applicable in this study and kempas is potential be used for biofuel production.
\end{abstract}

Key words: Kempas, ionic liquids, pretreatment.

\section{INTRODUCTION}

Fuels such as coal, natural gas, and oil are the main sources of energy for our daily activities. However, concerns about global warming and energy security have resulted in the exploration of alternatives for fossil resources to supply chemicals and energy ${ }^{1-2}$. Lignocellulosic biomass is a promising biofuel resource to replace fossil fuels as contains significant levels of cellulose and hemicelluloses which can be converted into bioethanol via saccharification and fermentation processes $^{3}$. However, saccharification of these untreated lignocellulosic biomass leads to low 
yields of the reducing sugars and this is a major obstacle in cellulosic ethanol production. Therefore, pretreatment, which disrupts the structure of the lignocellulosic biomass, is necessary to enhance the enzymatic hydrolysis and increase the yields of the reducing sugars. Different pretreatment methods, including physical, chemical, and a combination of physical/chemical processes commonly used in the pretreatment of lignocellulosic biomass, have been introduced in previous studies. Some of these methods, which require high pressure and temperature, produce corrosive and dangerous wastes, and may cause sugar degradation pretreated at high temperatures ${ }^{4-}$ 5 . Because of these shortcomings, alternative pretreatments are needed, of which, one using ionic liquids (ILs), a class of green solvents, has been reported in this study.

ILs with cellulose-dissolving ability offer a novel solution for pretreating lignocellulosic biomass, due to good solubilities, the competitive properties of cellulose reprecipitated from the ILS solutions, the increased stability of ILs and low toxicity of certain relevant ILs solutions ${ }^{6-7}$. Besides that, ILs are greener solvents since they can be recycled and reused in the dissolution process ${ }^{8}$. Based on previous studies on the ability to dissolve cellulose, 1-butyl-3-methylimidazolium acetate ([Bmim][OAc]), 1-butyl-3-methylimidazolium chloride $([\mathrm{Bmim}] \mathrm{Cl})$ and 1-butyl-3-methylimidazolium trifluoromethansulfonate ([Bmim][OTf]), were used as solvents in the pretreatment step to enhance reducing sugars yield in enzymatic hydrolysis in the present study ${ }^{9-11}$.

Malaysia is a tropical country rich in various types of tropical trees, and therefore, wood-based products can be produced in a large quantity. One of the lignocellulosic residues is kempas (Koompassia malaccensis). Many studies of lignocellulosic biomass for replacing conventional fuel sources have been carried out recently however studies regarding ILs pretreatment on kempas have not been reported elsewhere. Therefore, present work was carried to investigate the effects of various ILs (with different anionic groups) pretreatment on kempas in terms of composition, structural changes and enzymatic digestibility.

\section{MATERIALS AND METHODS}

\section{Reagents and Biomass Materials}

1-butyl-3-methylimidazolium acetate ([Bmim][OAc]), 1-butyl-3-methylimidazolium chloride ([Bmim]Cl) and 1-butyl-3methylimidazolium trifluoromethansulfonate ([Bmim][OTf]), Cellulast (cellulase from T. ressei), and Novozyme $188 \beta$-glucosidase (cellobiase from A. niger) were purchased from Sigma-Aldrich and used as received. The ground lignocellulosic biomass used in this study was kempas (Koompassia malaccensis), provided by the Forest Research Institute of Malaysia (FRIM). The lignocellulosic biomass was dried overnight in an oven at $105^{\circ} \mathrm{C}$ and kept in a dessicator prior to use.

\section{ILs Pretreatment of Lignocellulosic Biomass}

First, $5.4 \mathrm{~g}$ of different ILs were separately added to a glass test tube containing $0.5 \mathrm{~g}$ of lignocellulosic biomass inside the glove box in the presence of $\mathrm{N}_{2}$. The biomass/IL suspension was stirred at $500 \mathrm{rpm}$ at 120 for 6 and $12 \mathrm{~h}$ in a temperature controlled heating block on a hotplatestirrer (Heidolph, MR-Hei Standard) under a nitrogen atmosphere. After the pretreatment, the mixture was cooled to room temperature and mixed with $10 \mathrm{~mL}$ of distilled water. After $2 \mathrm{~h}$, the contents of the culture tube were transferred into Eppendorf tubes and centrifuged for $10 \mathrm{~min}$ at $10,000 \mathrm{rpm}$ (Scanspeed Mini) to obtain the regenerated biomass. The supernatant was removed and discarded while the suspension was filtered through a cellulose filter paper (Whatman 541 or equivalent) and further washed with $2 \times 10 \mathrm{~mL}$ of distilled water to remove any remaining ILs. Then, the sample was dried in an oven at 105 overnight. The dried regenerated biomass was then transferred into resealable air-tight sample bags ${ }^{12}$.

\section{Structural Characterization}

Field emission scanning electron microscopy (FESEM) analysis

FESEM was used to monitor the changes in the morphology before and after ILs pretreatment. A SUPRA 55VP (CARL ZEISS., Oberkochen, Germany) scanning electron microscope was used to image the samples. Prior to imaging, the samples were sputter-coated with platinum to make the fibers 
conductive, while avoiding degradation and buildup of charge on the specimen.

\section{Attenuated total reflectance fourier transform infrared (ATR FT-IR) analysis}

ATR FT-IR spectroscopy was performed using Perkin Elmer Spectrum 400. About $5 \mathrm{mg}$ of the sample material was placed on the diamond window. The background spectrum of the diamond window without the sample was subtracted from that of each sample spectrum. Scans were conducted in the $650-4000 \mathrm{~cm}^{-1}$ band.

\section{X-ray diffraction (XRD) analysis}

X-ray diffraction (XRD) was performed using a D8-Advance (BRUKER, Germany) XRD system. Patterns were collected from 10 to 60 (2) with step size of 0.025 at $8 \mathrm{deg} / \mathrm{min}$. Crystallinity index $(\mathrm{Crl})$ of the samples was computed by using Equation (1) ${ }^{13}$.

$$
C r I=\frac{I_{002}-I_{a m}}{I_{002}} \times 100
$$

Where $\mathrm{I}_{002}=$ maximum intensity of crystalline portion in sample at about $2 \theta=22.6^{\circ}$, $\mathrm{I}_{\mathrm{am}}=$ intensity attributed to the amorphous portion of kempas sample at $2 \theta=\sim 16^{\circ}$.

\section{Enzymatic Hydrolysis}

Enzymatic hydrolysis was performed according to LAP "Enzymatic saccharification of lignocellulosic biomass" (NREL/TP-510-42629). First, $150 \mathrm{mg}$ of the dried and pretreated/untreated biomass, $5 \mathrm{~mL}$ of $0.1 \mathrm{M}(\mathrm{pH} 4.8)$ sodium citrate buffer solution, and $100 \mu \mathrm{L}$ of $2 \%$ sodium azide solution were added to a $20 \mathrm{~mL}$ scintillation vial. The mixture was heated to 50 for specified times in a temperature controlled heating block on a hotplatestirrer (Heidolph, MR-Hei Standard); $60 \mu \mathrm{L}$ of Cellulast (cellulase from $T$. ressei) (Sigma-Aldrich) and Novozyme $188 \beta$-glucosidase (cellobiase from A. niger) (Sigma-Aldrich) each was added and the mixture was stirred at $250 \mathrm{rpm}$. Distilled water was added to bring the total volume to $10 \mathrm{~mL}$ after the addition of the enzymes.

Samples taken at different time intervals were analysed for total reducing sugar (TRS) using DNS method ${ }^{14}$. The DNS solution was prepared according to an IUPAC method ${ }^{15}(1416 \mathrm{~mL}$ distilled water, $10.6 \mathrm{~g}$ 3,5-dinitrosalicylic acid, $19.8 \mathrm{~g}$ sodium hydroxide, $306 \mathrm{~g}$ Rochelle salts/Na-K tartarate, 7.6 $\mathrm{mL}$ phenol melted at 50 , and $8.3 \mathrm{~g}$ sodium metabisulfite). The absorbance of the solution was read against the reagent blank at $540 \mathrm{~nm}$ as measured by a Shimadzu UV-Visible-1650 PC spectrophotometer (UV-VIS). The reducing sugar concentration in the sample was calculated based on a standard curve obtained with D-glucose.

\section{RESULTSAND DISCUSSION}

\section{Effect of Different ILs Pretreatment on Ground Kempas}

Field emission scanning electron microscopy (FESEM) analysis

Ground kempas was pretreated with three ILs: $[\mathrm{Bmim}][\mathrm{OAc}],[\mathrm{Bmim}] \mathrm{Cl}$ and $[\mathrm{Bmim}][\mathrm{OTf}]$. The

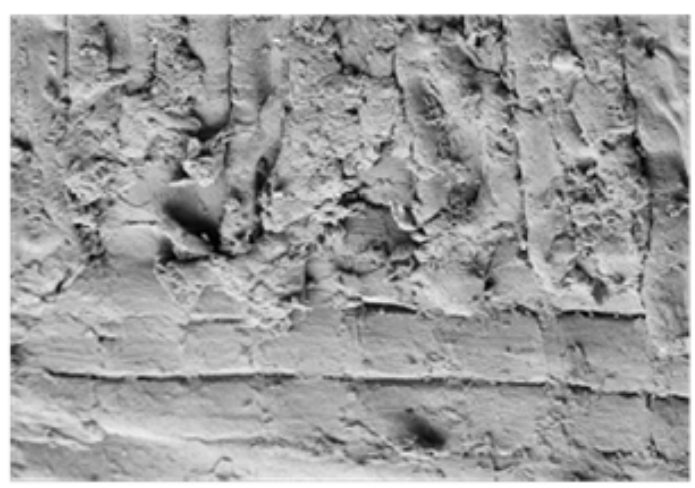

Fig. 1: FESEM images of untreated kempas

Table 1: Crystallinity index (Crl) of untreated kempas, regenerated cellulose pretreated with various ILs for 6 and $12 \mathrm{~h}$

\begin{tabular}{lc}
\hline $\begin{array}{l}\text { Ground kempas } \\
\text { sample }\end{array}$ & $\begin{array}{c}\text { Crystallinity } \\
\text { index (\%) }\end{array}$ \\
\hline $\begin{array}{l}\text { Untreated kempas } \\
\text { Regenerated cellulose ([Bmim][OAc] })\end{array}$ & 76.8 \\
$-6 \mathrm{~h}$ & 59.5 \\
$-12 \mathrm{~h}$ & 60.4 \\
Regenerated cellulose ([Bmim]Cl) & \\
$-6 \mathrm{~h}$ & 70.9 \\
$-12 \mathrm{~h}$ & 70.2 \\
Regenerated cellulose ([Bmim][OTf]) & \\
$-6 \mathrm{~h}$ & 66.7 \\
$-12 \mathrm{~h}$ & 69.0 \\
\hline
\end{tabular}


structural morphology of the untreated and pretreated ground kempas was examined by FESEM (Figures 1 and 2, respectively). It was observed (Figure 1) that the physical structure of the untreated ground kempas was compact and ordered.

After pretreatment, it can be seen (Figure 2) that the surfaces of all the pretreated ground kempas changed significantly and became rougher and disordered. The organized structure commonly present in native lignocellulosic biomass was absent, implying that the structure of the regenerated biomass was less crystalline and the results were in agreement with the findings of XRD and ATR FT-IR. Ground kempas from [Bmim][OAc]pretreatment was the most severely distrupted followed by $[\mathrm{Bmim}] \mathrm{Cl}$ - and [Bmim][OTf]pretreatments. [Bmim] $[\mathrm{OAc}]$-pretreatment of ground kempas also gave the highest TRS concentration in the enzymatic hydrolysis section. The distruption of the surface might have been caused by the solvating action of the $\mathrm{ILs}^{9}$. This also indirectly shows that the ILs pretreatment can reduce the crystallinity of cellulose compared to the untreated ground kempas so that it becomes more accessible to cellulase enzymes during saccharification.
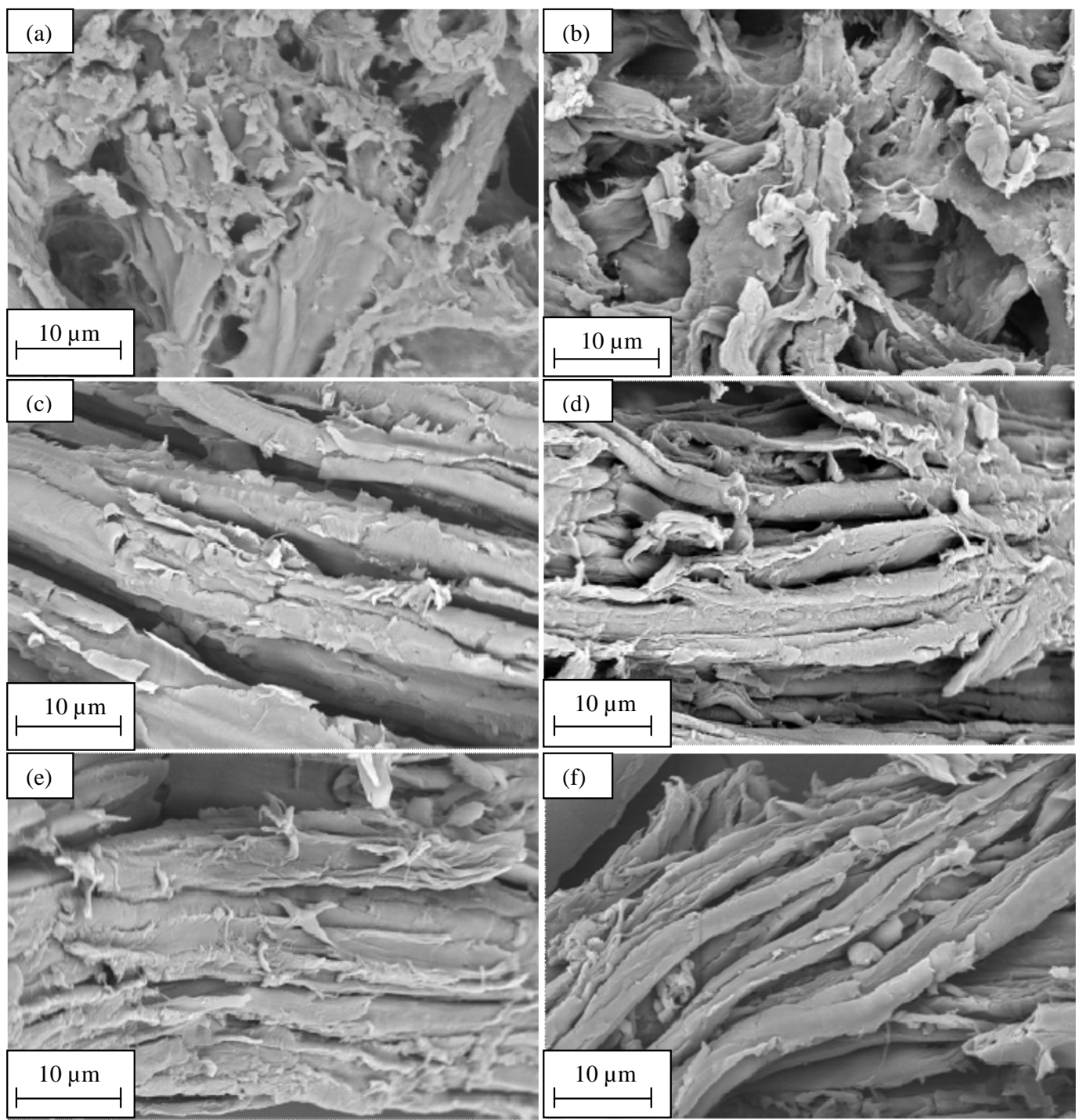

Fig. 2: FESEM images of ground kempas with (a) [Bmim][OAc] for $6 \mathrm{~h}$, (b) [Bmim][OAc] for $12 \mathrm{~h}$, (c) [Bmim] Cl for $6 \mathrm{~h}$, (d) [Bmim] Cl for $12 \mathrm{~h},(\mathrm{e})$ [Bmim][OTf] for $6 \mathrm{~h}$, (f) [Bmim][OTf] for $12 \mathrm{~h}$ pretreatments 
Attenuated total reflectance Fourier transform infrared (ATR FT-IR) analysis

After observing the changes in the kempas structure by FESEM, ATR FT-IR spectroscopy was used to obtain more indepth structural changes to cellulose or lignocellulosic biomass upon pretreatment (Figure 3) in the region $800-4000$ $\mathrm{cm}^{-1}$, which is commonly used to study the fine structural characteristics of cellulose ${ }^{16}$.

Native biomass consists of the lignincarbohydrate matrix since both cellulose/ hemicellulose- and lignin-associated bands can be
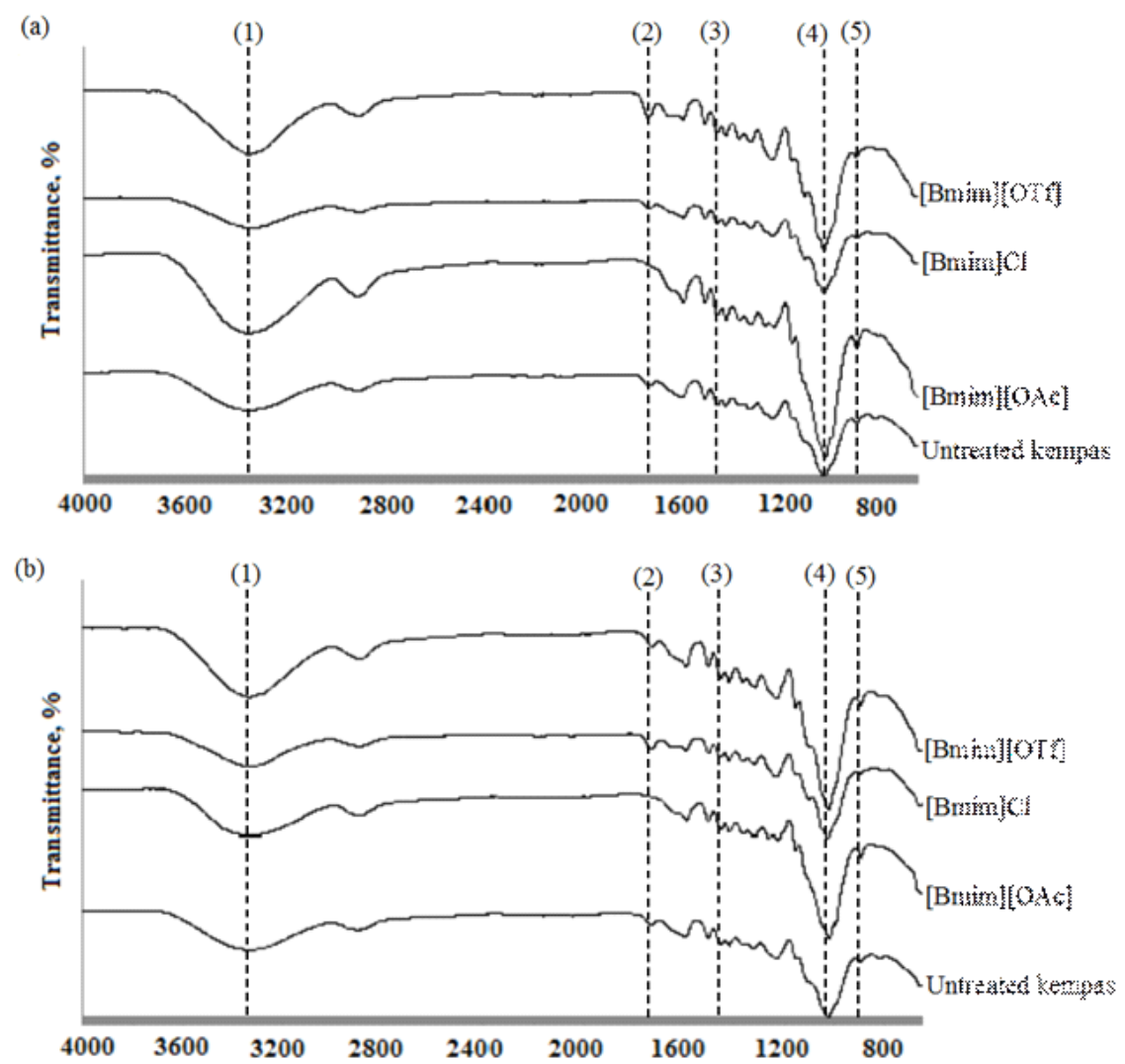

Fig. 3: ATR FT-IR spectral analyses of regenerated cellulose and untreated kempas. FT-IR spectral bands $\left(\mathrm{cm}^{-1}\right):(1)=3338 ;(2)=1732 ;(3)=1457 ;(4)=1048 ;(5) 895(a=$ pretreated for $6 \mathrm{~h} ; \mathrm{b}=$ pretreated for $12 \mathrm{~h})$
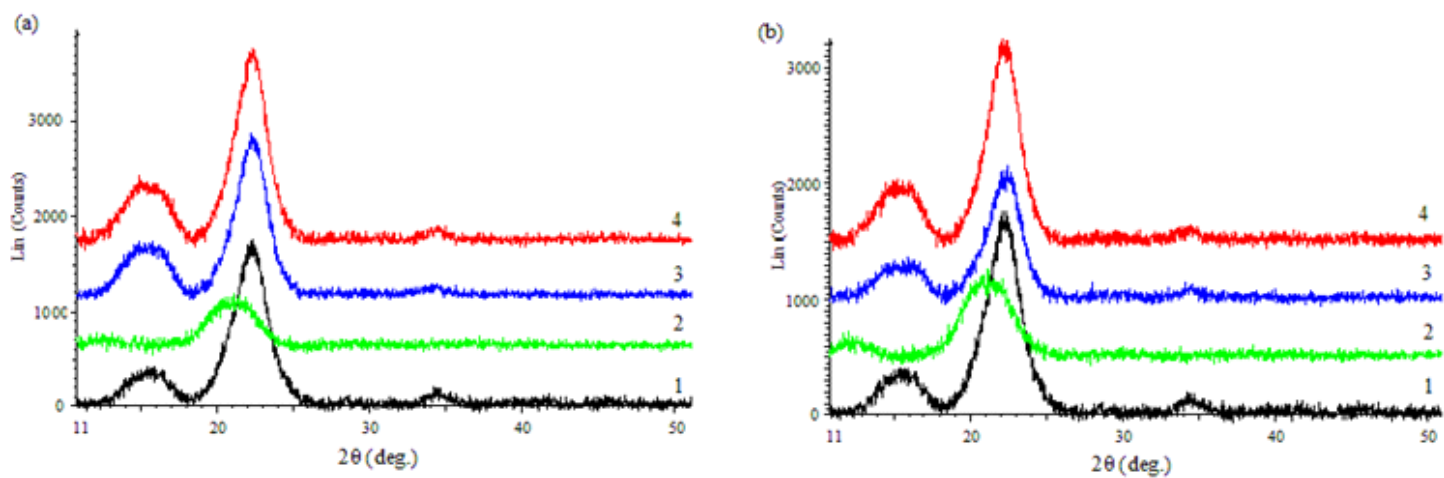

Fig. 4. XRD analyses of untreated and pretreated kempas ( $1=$ untreated kempas; $2=[\mathrm{Bmim}][\mathrm{OAc}]-$ treated; $3=[\mathrm{Bmim}][\mathrm{OTf}]$-treated; $4=[\mathrm{Bmim}] \mathrm{Cl}$-treated $)(\mathrm{a}=6 \mathrm{~h}$ pretreatment; $\mathrm{b}=12 \mathrm{~h}$ pretreatment $)$ 
observed in the spectrum of untreated biomass. It can be seen that the spectra of the regenerated kempas from the $[\mathrm{Bmim}][\mathrm{OAc}],[\mathrm{Bmim}] \mathrm{Cl}$ and [Bmim][OTf] pretreatment for 6 and $12 \mathrm{~h}$ were almost the same. Basically, from the spectra of all the regenerated biomass, the strongest absorption band was found to be at approximately $1048 \mathrm{~cm}^{-1}$, which corresponds to the $\mathrm{C}-\mathrm{O}$ stretching vibration in both cellulose/hemicellulose and lignin ${ }^{17}$. The peak at $1732 \mathrm{~cm}^{-1}$ is associated with the $\mathrm{C}=\mathrm{O}$ stretch in unconjugated ketones, carbonyls and esters groups ${ }^{18}$. The peak at $1457 \mathrm{~cm}^{-1}$ which is corresponding to asymmetric bending of $\mathrm{CH}_{3}$ and methoxy $\left(-\mathrm{OCH}_{3}\right)$ groups present in lignin ${ }^{17}$, was present in all spectra, this implying that lignin remained in the matrix. Moreover, a strong absorption band at around $3338 \mathrm{~cm}^{-1}(-\mathrm{OH}$ stretching) was observed in the all spectra, which could be due to moisture absorption. [Bmim][OAc]treated kempas showed highest intensity at band $895 \mathrm{~cm}^{-1}$ and the peak at $1732 \mathrm{~cm}^{-1}$ was disappeared for both pretreated for 6 and $12 \mathrm{~h}$, implying that the regenerated cellulose was more amorphous than the others. According to Ang et al. ${ }^{9}$, the band at around $800 \mathrm{~cm}^{-1}$ is sensitive to the amount of amorphous cellulose present in the regenerated material, and broadening of this band indicates the higher amorphousity of the regenerated cellulose.

In comparison, there were no significant changes on the spectra of regenerated lignocellulosic biomass from the $[\mathrm{Bmim}] \mathrm{Cl}$ and [Bmim][OTf] pretreatments. In the spectra of the regenerated lignocellulosic biomass of these two ILs, the band at around $895 \mathrm{~cm}^{-1}$ was broader, implying a higher amount of the disordered cellulosic structure. The disordered cellulosic structure is possibly caused by the deformation of the glycosidic linkages and hydrogenbond rearrangement, as reported by Proniewicz et al. ${ }^{19}$.

Overall, among the regenerated cellulose, [Bmim][OAc]-treated cellulose showed clear changes in the ATR FT-IR spectral pattern, indicating that the $[B m i m][O A c]$ pretreatment was more effective in the distruption of hydrogen bonds ${ }^{20}$ than the $[\mathrm{Bmim}] \mathrm{Cl}$ and $[\mathrm{Bmim}][\mathrm{OTf}]$ pretreatments. The type of anion species of ILs is a critical determinant on the weakening of hydrogen bonds of cellulose ${ }^{21}$.
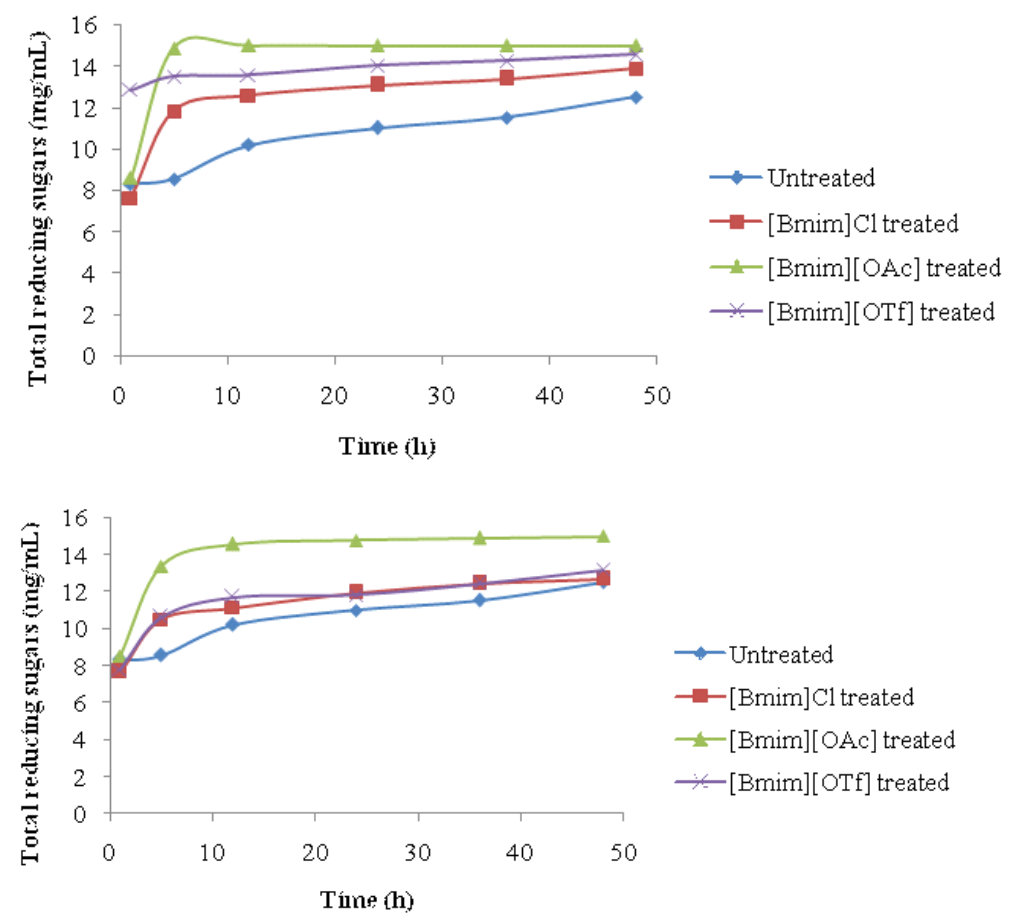

Fig. 5: Effect of ILs on the enzymatic hydrolysis of untreated and ground kempas pretreated for (a) $6 \mathrm{~h}$ and (b) $12 \mathrm{~h}$ 
However, due to heterogeneous nature of plant cell wall, direct assessment of chemical changes at the molecular level cannot be accomplished by using ATR FT-IR spectroscopy alone.

\section{X-ray powder diffraction (XRD) analysis}

XRD analysis was conducted to further investigate the crystallinity of lignocellulose. Figure 4 shows the diffraction patterns of untreated and pretreated kempas with various ILs. There were two obvious peaks in both the untreated and pretreated kempas. The first peak was broad at $16^{\circ}$. The second peak appeared at around 22 for kempas. These peaks are known as the crystalline peaks or $\mathrm{I}_{002}$ which indicate the presence of cellulose $\mathrm{I}^{22}$. At this peak, untreated kempas showed higher and sharper diffraction than the regenerated cellulose from various ILs pretreatment, implying that the untreated kempas is qualitatively more crystalline than the others. After the ILs pretreatment, the main peak was observed to be broadened and of lower intensity for all the regenerated cellulose pretreated with various ILs. The broadening of the peak indicates a decrease in crystallinity upon IL pretreatment ${ }^{23}$.

The quantitative crystallinity of the untreated and regenerated kempas was estimated using Equation 1. Table 1 shows the crystallinity index (Crl) of both untreated and pretreated kempas. Generally, the lower $\mathrm{Crl}$ indicates a higher amount of amorphous cellulose present in the regenerated cellulose ${ }^{24}$. The $\mathrm{Crl}$ of untreated kempas was $76.8 \%$. It can be seen that $\mathrm{Crl}$ of both cellulose from ILs for 6 and $12 \mathrm{~h}$ was almost the same. Among the regenerated cellulose, cellulose regenerated from the 6 and $12 \mathrm{~h}$ pretreatment of [Bmim][OAc] showed the lowest $\mathrm{Crl}$, which was $59.5 \%$ and $60.4 \%$, respectively. It was then followed by [Bmim][OTf]with $66.7 \%$ for $6 \mathrm{~h}$ pretreatment and $69 \%$ for $12 \mathrm{~h}$ pretreatment. Cellullose regenerated from the pretreatment of $[\mathrm{Bmim}] \mathrm{Cl}$ gave the lowest $\mathrm{Crl}$ with $70.9 \%$ for $6 \mathrm{~h}$ pretreatment and $70.2 \%$ for $12 \mathrm{~h}$ pretreatment. However, there was a slightly increment of $\mathrm{Crl}$ for $12 \mathrm{~h}$ pretreatment for both [Bmim][OAc] and [Bmim][OTf]. This might due to the degradation of ILs as the experiment run at 120 and decreased the cellulose-dissolution efficiency. Also, there were no significant effects on $\mathrm{Crl}$ after pretreatment with [Bmim] $[\mathrm{Cl}]$ for 6 and $12 \mathrm{~h}$, possibly because the conversion of the cellulose crystalline structure was from cellulose I to II, rather than an alteration to amorphous cellulose. The decrease in $\mathrm{Crl}$ enabled the cellulase enzymes easier access to hydrolyze cellulose ${ }^{22}$. The decrease in the crystallinity of the regenerated cellulose of kempas is supported by FESEM, ATR FT-IR analysis and enzymatic hydrolysis.

\section{Effect of Pretreatment on Enzymatic Hydrolysis}

Enzymatic hydrolysis of the regenerated lignocellulose was carried out to investigate the digestibility from ILs pretreatment. The enzymatic hydrolysis yield for the untreated and pretreated samples with 6 and $12 \mathrm{~h}$ pretreatment durations are shown in Figure 5. Overall, it was observed that the regenerated lignocelllose exhibited higher concentration of TRS compared to their counterparts. TRS concentration of untreated ground kempas was $12.5 \mathrm{mg} / \mathrm{mL}$. At the $48^{\text {th }}$ hour of hydrolysis, among the ILs studies, [Bmim][OAc]regenerated cellulose showed the highest TRS concentration $(15.0 \mathrm{mg} / \mathrm{mL})$ for both pretreated for 6 and $12 \mathrm{~h}$. The pretreatment of ground kempas with [Bmim][OTf] for 6 and $12 \mathrm{~h}$ resulted in TRS concentration of $14.6 \mathrm{mg} / \mathrm{mL}$ and $13.2 \mathrm{mg} / \mathrm{mL}$, respectively. Lastly [Bmim] Cl-regenerated cellulose for 6 and $12 \mathrm{~h}$ showed $13.9 \mathrm{mg} / \mathrm{mL} 12.7 \mathrm{mg} / \mathrm{mL}$, respectively, after $48 \mathrm{~h}$ of hydrolysis.

Anion of ILs plays an important role in determining ILs ability to dissolve cellulose. For cellulose solubility, it was shown that ILs that dissolves cellulose are attributed to strong hydrogen-bonding interactions between the anions and equatorial hydroxyl groups on the cellulose. The hydrogen-bond basicity/value of $\beta$ is primarily influenced by the anion ${ }^{21}$. As studied by Brandt et al. ${ }^{25}$, the value of [Bmim][OAc] is higher than that of [Bmim] Cl and [Bmim][OTf] showed lowest value. Therefore, the ILs trend of the TRS yield from the enzymatic hydrolysis of the regenerated lignocellulose should be $[\mathrm{Bmim}][\mathrm{OAc}]>[\mathrm{Bmim}] \mathrm{Cl}>$ [Bmim][OTf]. However, in this experiment, the ILs trend of the TRS yield from the enzymatic hydrolysis of the regenerated lignocellulose was [Bmim][OAc] $>[$ Bmim $][\mathrm{OTf}]>[\mathrm{Bmim}] \mathrm{Cl}$. The possible reason for this is the reduced melting point and viscosity of [Bmim][OTf] (m. p: -15) compared to [Bmim]Cl (m. p: $70)$. 
It can be observed that the TRS yield of the regenerated cellulose with various ILs for $6 \mathrm{~h}$ exhibited the same or slightly better TRS yield than that for $12 \mathrm{~h}$. This was attributed to the temperature of pretreatment as the experiment was carried at 120 and at such a high temperature, it is likely that some of the ILs degraded during the treatment ${ }^{25}$. Sathitsuksanoh et al. ${ }^{26}$ compared the effect of concentrated phosphoric acid (COSLIF, 85\%) and $[\mathrm{Bmim}] \mathrm{Cl}$ on the saccharification yield of both pure cellulose and corn stover. The COSLIF process was run at only $50{ }^{\circ} \mathrm{C}$ and was shown to result in higher saccharification yields than the $[\mathrm{Bmim}] \mathrm{Cl}$ pretreatment.

From all the findings that we obtained, this study demonstrated that kempas which is one of the main wastes of wood-based production in Malaysia has a great potential in biofuel production by using environment-friendly ILs preatment method and is a beneficial alternative for conversion of biomass into value added-products.

\section{CONCLUSION}

The study found that the chemical composition of regenerated cellulose varies with the type of ILs used. After pretreating with various ILs, the regenerated cellulose was more amorphous and had lower crystallinity than the untreated kempas, which can enhance enzymatic hydrolysis. Among the ILs, kempas pretreated with [Bmim][OAc] for 6 and $12 \mathrm{~h}$ exhibited significant highest TRS yield and followed by [Bmim] Cl and [Bmim][OTf]. Since the TRS yield of the pretreatment of ground kempas with ILs for $6 \mathrm{~h}$ exhibited the same or slightly better TRS yield than that for $12 \mathrm{~h}$, indicating that shorter pretreatment time is more applicable in this study.

\section{ACKNOWLEDGEMENTS}

We acknowledge Universiti Kebangsaan Malaysia for the financial support via the research grants AP/2012/017 and ERGS/1/2013/TK07/UKM/ 02/4 and the supporting staff of School of Chemical Sciences \& Food Technology that has contributed greatly in our research. We are also grateful to Forest Research Institute Malaysia (FRIM) for providing the samples.

\section{REFERENCES}

1. Saidur, R.; Abdelaziz, E. A.; Demirbas, A.; Hossain, M. S. Mekhilef, S.; Renewable \& Sustainable Energy Reviews, 2011, 15, 2262-2289.

2. Martin, M.; Eklund, M.; Biomass and Bioenergy, 2011, 35, 1747-1755.

3. Balat, M.; Energy Conversion and Management, 2011, 52, 858-875.

4. Chandra, R. P.; Bura, R.; Mabee, W. E.; Berlin, A.; Pan, X.; Saddler, J. N.; Advances in Biochemical Engineering/Biotechnology, 2007, 5, 904-910.

5. Sun, Y.; Cheng, J.; Bioresource Technology, 2002, 83, 1-11.

6. Qian, W.; Jin, E.; Bao, W.; Zhang, Y. G.; Angewandte Chemie International Edition, 2005, 44, 952-955.

7. Dupont, J.; Souza, R. F. D.; Suarez, P. A. Z.; Chemical Reviews, 2002,102, 3667-3692.
8. Zhu, S.; Wu, Y.; Chen, Q.; Yu, Z.; Wang, C.; Jin, S.; Ding, Y.; Wu, G.; Green Chemistry, 2006, 8, 325-327.

9. Ang, T. N.; Ngoh, G. C.; Chua, A. S. M.; Lee, M. G.; Biotechnology for Biofuels, 2012, 5, 6777.

10. Lee, S. H.; Doherty, T. V.; Linhardt, R. J.; Dordick, J. S.; Biotechnology and Bioengineering, 2009, 102, 1368-1376.

11. Pu, Y. Q.; Jiang, N.; Ragauskas, A. J.; Journal of Wood Chemistry and Technology, 2007, 27, 23-33.

12. Brandt, A.; Ray, M. J.; To, T. Q.; Leak, D. J.; Murphyb, R. J.; Welton, T.; Green Chemistry, 2011, 13, 2489-2499.

13. Segal, L.; Creely, J. J.; Martin, A. E. Jr.; Conrad, C. M.; Textile Research Journal, 1959, 29, 786-794.

14. Miller, G. L.; Analytical Chemistry, 1959, 31, 
426-428.

15. Ghose, T. K.; Pure and Applied Chemistry, 1987, 59, 257-268.

16. Hurtubise, F. G.; Krassig, H.; Analytical Chemistry, 1960, 32, 177-181.

17. Labbe, N.; Rials, T. G.; Kelley, S. S.; Cheng, Z. M.; Kim, J. Y.; Li, Y.; Wood Science and Technology, 2005, 39, 61-77.

18. Muller, G.; Bartholme, M.; Kharazipour, A.; Polle, A.; Wood Fiber Science, 2008, 40, 532543.

19. Proniewicz, L. M.; Paluszkiewicz, C.; Weselucha-Birczynska, A.; Majcherczyk, H.; Baranski, A.; Konieczna, A.; Journal of Molecular Structure, 2001, 596, 163-169.

20. Zhang, H.; Wu, J.; Zhang, J.; He, J.; Macromolecules, 2005, 38, 8272-8277.

21. Ab Rani, M. A.; Brandt, A.; Crowhurst, L.; Dolan, A.; Hallett, J. P.; Hassan, N. H.; Hunt, P.
A.; Lui, M.; Niedermeyer, H.; Perez-Arlandis, J. M.; Schrems, M.;To, T. Q.; Welton, T.; Wilding, R.; Physical Chemistry Chemical Physics, 2011, 13, 16831-16840.

22. Cheng, G.; Varanasi, P.; Li, C.; Liu, H.; Melnichenko, Y. B.; Simmons, B. A.; Kent, M. S.; Singh, S.; American Chemical Society, 2011, 12, 933-941.

23. Çetinkol, O. P.; Dibble, D. C.; Cheng, G.; Kent, M. S.; Knierim, B.; Auer, M.; Wemmer, D. E.; Pelton, J. G.; Melnichenko, Y. B.; Ralph, J.; Simmons, B. A.; Holmes, B. M.; Biofuels, 2010, 1, 33-46.

24. Kuo, C. H.; Lee, C. K.; Carbohydrat Polymers, 2009, 77, 41-46.

25. Brandt, A.; Grasvik, J.; Hallett, J. P.; Welton, T.; Green Chemistry, 2013, 15, 550-583.

26. Sathitsuksanoh, N.; Zhu, Z.; Zhang, Y. H. P.; Cellulose, 2012, 19, 1161-1172. 